\title{
LA INUTILIDAD \\ DEL \\ ETNOCENTRISMO
}

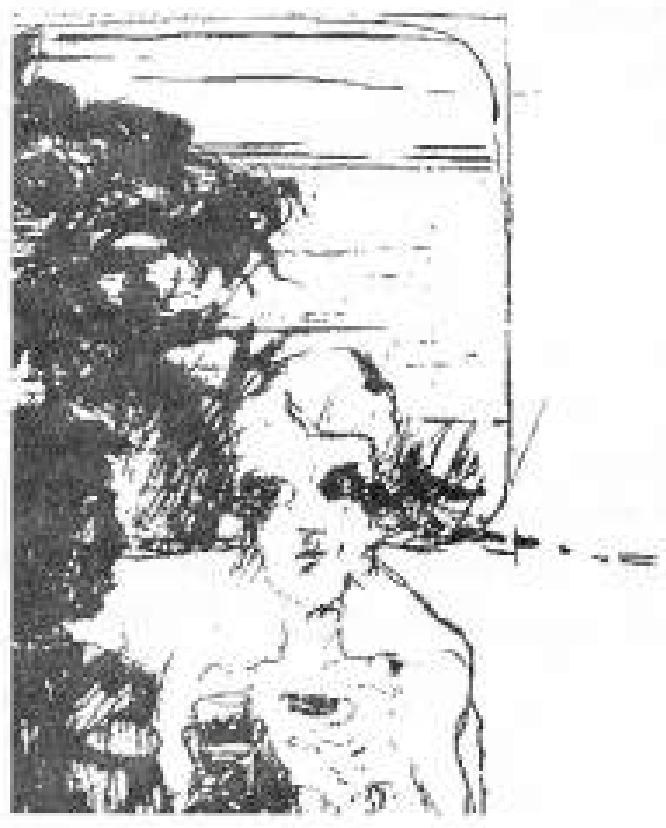

\section{PALLAC. VANEGASBETANCOURTH \\ Odontologa. Profesora Asistente \\ Facularad de Odontologia \\ Universidad Autónoma de Manizales}

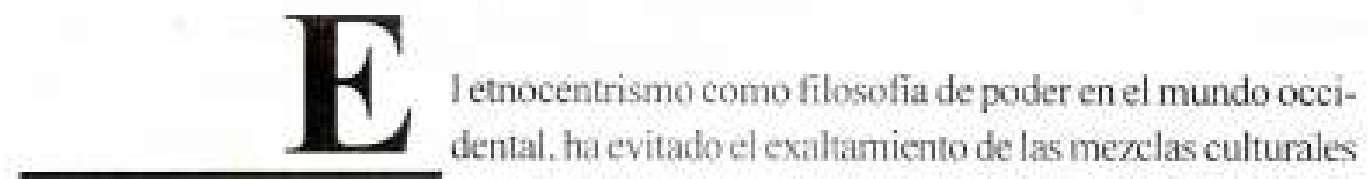

como opción de vida. dándole a las minorias un lugar en los suburbios del eonocimiento y de la ciencia.

La exclusión de las fuentes de conocimiento primitivo por el hombre contemporáneo, le permite la sensación de dominio sobre el mismo hombre y sobre la natualeza.

La industrialización le permitió al hombre, como lo menciona David Dickson: "El supuesto dominio sobre la nataraleza y la aplica- 
ción de las fuerzas naturales a sus propios fines»', pero a su vez, ha perdido hectáreas de selvas hủmedas en la Amazonia, ha fera y ha precipitado la extinción de diversas especies de flora y fauna, causando un desequilibrio ecológico que ha llevado al gasto de rubros públicos en la investigación para la recuperación del medioambiente.

El monopolioejercido por el hombre occidental, si bien ha sido generado a partir de la teorización y el desarrollo de las ciencias , ha minimizadoexpresiones cientificas que podrian ser aprovechadas como Tecnologias Altemativas.

\section{SOBRE LAS OTRAS TECNOLOGIAS}

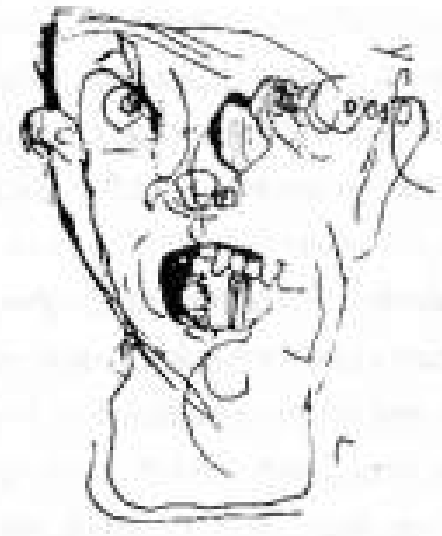
implementación de terrazas el aprovechamiento de tierras agrestes y realizaron la planificación de cultivos con base en calendarios clímatológicos, respetandoel ecosistema y disminuyendo el impacto negativo sobre el ambiente: pues si este equilibrio no era mantenido, los indigenas aseguraban que se produciria un suceso en producido agujeros en la atmós-

Uno de los grandes legados indigenas es, como lo expresa Reichel Dolmattoff: «La gran enseñanza ecologica, de hido a que estas culturas supieron adaptarse a una naturaleza hravia, y al mismo tiempo crear sus culturas sin que in el proceso sufrieran las selvas y las sabanas como sucede hoyw?

Si bien los pucblos modemos no se pueden apartar de la teorización y la cientificidad. el compartir el conocimiento ances. tral permitiria retomar caminos ya labrados por diversas culturas

\section{ENFERMEDAD VS CURA- CIÓN, UNA OPTICA MÚLTIPLE}

Una de las ciencias que ha tenido mayor desarrollo y a la vez ha menospreciado el acerbo tradicional. es la medicina con sus conceptos de salud y enfermedad, a los cuales me acercare haciendo un barrido histórico breve. contra de la propia comunidad.
Bajo la óptica de Susan Sontag en el ensayo " La enfermedad y sus metáforass; $*$ A la enfermedad se le asignun los horrores más hondes, lla corrupción, la putrefacción, la polución. la anomia y la de hilidad $/ \mathrm{m}^{1}$

La enfermedad ha sido vista por 
los occidentales en múltiples formas a través del tiempo. Para los griegros representa una posesión demoniacat o un castigo sobrenattural. Posteriomente. en la Edad Media. cobra vigencia laconcepción judeo-cristiana punitiva de la enfermedad.

Contemporancamente su explicación ha sido puramente anatómico-patológica; algunas veces se le han dado explicaciones psicológicas. pero éstas han sido obviadas al hacer el diagnóstico y tratamiento.

Por mediodel vocabulario técnico y los descubrimientos microbiológicos de los patógenos causales. la enfermedad ha dejado de ser un mito para la comunidad médica. Suestudio se ha vuelto exclusivo de una disciplina $\mathrm{e}$ igualmente ha sido encaminado únicamente hacia el cuerpo, el cual es al mismo tiempo el huésped para el patógeno y el objeto a ser tratado.

Es asi como la salud pública se havisto. segũn Ramirez-Espinel: "Inmersa en un mundo cientifito, en donde la enfermedody la muerte, han quedado reducidas a problemas técricos y burocraticas $n^{4}$ La concepción de la enfermedad por la sociedad occidental ha estrechado la visión del ser y ha encaminado su estu- dio exclusivamente hacia el onganismo en sus funciones celulares y quimicas. Por lo tanto, el adelanto cientifico - técnico ha sido preponderado para llevar a cabo el diagnóstico y el tratamiento de la enfermedad desde dicho enfoque.

* La élite poseedora del conocimiento, se cree con el debery el derecho civilizador de lomar decisiones sobre la población. incluso en contra de suconsentimiento $\alpha^{4}$. Esta afirmación hecha por Restrepo-Espinel en el libro: "Semiología de las Prácticas de la Salud". muestra la

\section{"A la enfermedad se le asignan los horrores más hon- dos, (la corrup- ción, la putrefac- ción, la polución, la anomia y la debilidad"}

magnipotencia a la que el tecnocratismo ha llegadoen nuestracultura.

La disociación del ser, su no reconocimiento como el engranaje alma-cuerpo. y además como parte de una sociedad en la cual el es participativo, que lo afectay es afectada por él. parece ser la constante de la medicina moderna en la actualidad.

La conciencia de la muerte y la caracterización de la enfermedad como una condición humana presente en grupos indigenas americanos como los Nanuath. se contrapone al mito modemo en donde la salud es vista como sinónimo de felicidad y la negación de la muerte hace parte de esta filosofia.

En la cultura Wayuu de La Guajira, se afirma, según el antropólogo Michel Perrin que: $\alpha$ La persona esta formada de un cuerpo igual a carne y de sn alma igual a corazón siendo éste el asien. to del alma ${ }^{\phi}$, además se reconoce la interacción del ser en el grupo social. como confonmador y participe de la sociedad tribal.

Es asi como para los Wayuu. la enfermedad es una responsabilidad grupal y su cura es buscada no sólo en el cuerpo (carne) sino también en el entorno; igual que para otras culturas amazónicas según lo afirmado por el antropólogo Josep $\mathrm{M}^{\circ}$ Fericgla. «La mayor parte de las acrintdades de los chamanes, pueden ser comprendidas como actos caya áltima finalidad és la gesfión de las recursos y del equilibrio social por medio de una re- 
lacion de ayuda a nivel individual y colectivos.

ElChamán utiliza los sueños como medio para conocer la enfermedad: los wayuu utilizanéstos como un lenguaje colectivo $y$ de sanación. El Chamán, a través de lo onirico y por medio de interpretaciones, bien sea por analogias, por inversión, por correspondencia por clasificación o por homologia, diagnostica y cura, por medio de la utilización de medicamentos naturales y la realización de la sanación de los individuos y del entomo social comprometido con la enfermedad y por ende con la cura:

Para los indigenas Wayuu, el sueño es visto como un vagabundo noctumo, la enfermedad como un errar prolongado y la muerte como un irse definitivo, que no puede ser desperdiciado. Para ellos la muerte no es el fin, se cree que es el inicio de una cadena de transformaciones para llegar a un estado final ${ }^{s}$.

\section{DE LA EXCLUSIÓNA LA INCLUSIÓN}

Cuando se realiza un sincretismo entre las concepciones indigenas y las occidentales. como se daen el Hospital Wayuu de la Guajira. en donde se relacionan. el chamán con su interpretación de la sintesis: enfermedad -individuo - sociedad - relaciones - sucño, $y$ el médico occidental con su concepción basada en la interpretación pathos - medicación - quimica - cura, se observa que el espacio ganado por la mezcla no separatista ni excluyente de las culturas, da como resultado una concepción menos disociativa y tecnocratica del ser bumano, y se favorece al individuo y a su bienestar, el cual se hace participe de su proceso de curación sin ser

\section{«La gran enseñanza ecológica, debido a} que estas culturas supieron adaptarse a una naturaleza bravía, y al mismo tiempo crear sus culturas sin que en el proceso sufrieran las selvas $y$ las sabanas como sucede hoy".

agredido en sus creencias y mitos y sin ser visualizado como organismo puramente celular.

Es asi como la fusión y el encuentro entre las culturas provee una visión más amplia en la interpretación de un problema determinado que genera impacto en la sociedad.
El campo de la medicina podria verse ampliado en el àmbito de la farmacologia con la inclusión de medicamentos no quimicos para la cura de enfermedades -conocimiento ya obtenido por las culturas milenarias-, además de la implementación de la visión complejay completa del ser integral y social, en donde la interacción oun su medio repercute en su salud y por ende en su mantenimiento y cura. la cual no solamente depende del vademécum, sino también. de la sanación y del entendimiento del entomo social.

Asi mismo, ta conciencia coológica y el protagonismo del aprovechamiento de los recursos naturales. concomitante con el respeto por la umadre tierras, constituye una práctica asimilable por la agricultura y mineria moderna.

Es entonces, cuando el hombre actual -que ha jugado con el poder masivo, excluyente de las minorias y con el dominio del conocimiento-. podria acercarse a su pasado, a las otras culturas.

\section{LA SUPREMACIA DE LA INTERACCIÓN}

La heterogeneidad racial no debe ser entendida sólo como una mez: cla étnica. sino como oportunidad 
para realizar una combinación de conocimientos.

Las culturas aborigenes han sido resignadas al establecimiento de resguardos, vieja forma de dominación española profundamente estudiada por Margarita González en nEl resguardo en el Vuevo Rejno de Granadan". y definida como la forma más fácil para tener el poder sobre la mano de obra barata. El resguardo aparece en la actualidad como figura de protección que impide la interacción y que termina por reducir al anonimato y a la extinción a la población minoritaria, pues, si bien la conservación de su cultura depende en cierto grado del aislamiento. éste se revierte para ser el censurador y el homicida de la cultura indigena.

El reconocimiento pues. de lo diferente, abona la consecución de una globalización que permita la observancia de diversos imaginarios colectivos como punto de partida para una sociedad pluralista, heterogénea. que comprenda la mexclacultural como la piedra angular para la evolución y fortalecimiento de la ciencia. 米

\section{BIBLIOGRAFIA}

I. GALEANO. EDUARDO nMemoria de Fuego to Los Nacimientos. Editorial siglo veitiuno. Primera edición 1982

2. RESTREPO, LUIS CARLOS, ESPINEL, MANUEL. *Semiologia de las prácticas de la salud. " editorial CEJA 1996

3 ENTRFVISTAA TAITALUCIANOMUTUMBAY. Revista Visión Chamanica. No 1 febrero 1900. Pag 30

4 SONTAG,SUSAN, aLa enfermedad y sus melaiforaso Editorial Santillana-Tauns 1996.

5. CASTROCAICEDO, GERMAN w Hagase tu voluntado editorial Planeta 1998

6. REICHEL-DOKMATOFF, GERARDO, acolombia indigenaw Editorial Colina 1998.
7. GONZALEZ, MARGARITA, «EI Resguardo en al Nuevo Reino de granadas Universidad Nacisnai de Colombia. 1970.

8. HERNANDEZ, CAMILOANTONIO, HEl Jaibuna: La cazay la pesca× Rev. Ecologica pag 12-17 N07,1991.

9 BOTERO,SYLVIA Y COL w La sierra aserrada o la madre sierraw Rev Ecologica pag 48-52. N" 71991.

10. DROHER.CYRII. undios Kogi. L.os vigulantes de la tierrav Rev Muy Interesante. No 168 pay. 63-73. 1999 .

11. SALASPICON, MARIANO wObras selectas», Ediciones Edime.Madrid-Caracas. 1953.

12. DICKSON, DAVID "Teciologia Alternativan Editorial Orbis. Barcelona, 1985.

13. FERICGLA .OOSEPMARIA. EEI peso central de los enteógenos en la dinámica culturalo Rev Visionn Chamánica. ND1, pag 28-35 febrero 1999

' Dickson, david, "Tecnologia Alternativa. Editorial Orbis Barceloxta,1985.pag 53

${ }^{2}$ Reichel-Dolmatoff, gerardo "Colombia indigena" editorial Colina 1998

"Sontag.Susan "La enfermedad y sus metaforas" Edición Santillana,taurus, 1996.pag 61

+ Restrepo, Luis Carlos, Espinel, Manuel. "Semiologia de las prícticas de Salud". CEJA. 1996 . pay 234.

'Ibidem, pag

- Periin Michel. "Les Practiciens du Reve . Un example de Chamanisme-editoral PUI 1992

${ }^{3}$ Fericgla, Josep $\mathrm{M}^{0}{ }^{-}$El peso ceniral de los enteógenos en la diaámica cultural" Visión Chamánica I. Feb. 1499 p30

"Michel Perrin du Reve Les Practiciens du Reve " Un example de chamanisme" PUF 1992

"Gonzaiez Margarita. El resguardo en el Nuevo Reino de Granada" Universidad nal de Colombia. $1970 \mathrm{~B}$ 